\title{
The traffic and behavioral effects of the I-35W Mississippi River bridge collapse
}

\author{
Shanjiang Zhu*, David Levinson, Henry X. Liu, Kathleen Harder \\ University of Minnesota, Department of Civil Engineering, 500 Pillsbury Drive SE, Minneapolis, MN 55455, USA
}

\section{A R T I C L E I N F O}

\section{Article history:}

Received 6 August 2008

Received in revised form 15 June 2010

Accepted 4 July 2010

\section{Keywords:}

I-35W bridge collapse

Travel behavior

Travel survey

\begin{abstract}
A B S T R A C T
On August 1, 2007, the collapse of the I-35W bridge over the Mississippi River in Minneapolis abruptly interrupted the usual route of about 140,000 daily vehicle trips, which substantially disturbed regular traffic flow patterns on the network. It took several weeks for the network to re-equilibrate, during which period travelers continued to learn and adjust their travel decisions. A good understanding of this process is crucial for traffic management and the design of mitigation schemes. Data from loop-detectors, bus ridership statistics, and a survey are analyzed and compared, revealing the evolving traffic reactions to the bridge collapse and how individual choices could help to explain such dynamics. Findings on short-term traffic dynamics and behavioral reactions to this major network disruption have important implications for traffic management in response to future scenarios.
\end{abstract}

(c) 2010 Elsevier Ltd. All rights reserved.

\section{Introduction}

On August 1, 2007, the collapse of the I-35W bridge over the Mississippi River in Minneapolis abruptly interrupted the usual route of about 140,000 daily vehicle trips, which substantially disturbed regular traffic flow patterns on the network. It took several weeks for the network to re-equilibrate, during which period travelers continued to learn and adjust their travel decisions. This process is not well understood due to the limited number of major network disruptions. Moreover, traffic monitoring devices are usually not readily available surrounding the disruption site. Consequently, data collection efforts are limited in the aftermath of unpredictable disruptions. This may partly explain why most studies of major network disruptions look only at one snapshot in time, usually a relatively long time after the incident. Fewer studies look at what happens immediately after a network disruption.

This natural experiment of prolonged, large-scale network disruption provides a unique opportunity to investigate how travelers react to such incidents over a short and medium time period. Since the re-equilibration process occurred within a short time frame, this process, for the most part, excludes the effects of long-term decisions such as work and residential location. After the bridge collapsed, a survey was conducted that targeted travelers who were likely to be affected by this incident. Respondents reported their commute travel pattern over time. Traffic data from loop-detectors and bus ridership during the same time periods were also collected. We compared the information from different sources to reveal the evolving traffic reactions to the bridge collapse and how individual choices could help to explain such dynamics.

\footnotetext{
* Corresponding author. Tel.: +1 612626 0024; fax: +1 6126267750 .

E-mail addresses: zhuxx120@umn.edu (S. Zhu), dlevinson@umn.edu (D. Levinson), henryliu@umn.edu (H.X. Liu), harde015@umn.edu (K. Harder). URL: http://nexus.umn.edu (D. Levinson).
} 
This paper investigates aggregate traffic patterns and underlying travelers preference in response to a major network disruption based on the data collected immediately after the memorable collapse of the I-35W bridge. After a general review of existing research in this field, data from three different sources are presented in detail. Conclusions will be made after a discussion of findings.

\section{Literature review}

Network disruptions caused by infrastructure failure are unusual but not unknown. In recent years, we have seen the collapse of the I-80 San Francisco-Oakland Bay Bridge and I-880 Cypress Street Viaduct due to the Loma Prieta Earthquake, the Hatchie River Bridge in Tennessee, and the I-40 bridge at Webbers Falls, Oklahoma, among others. Networks may be disrupted by other disasters (such as 9/11 or Hurricane Katrina), and more commonly, construction and maintenance work. The impacts of such incidents may vary in both the geographic (i.e. a strike by an earthquake could partially damage links over a large area, while a bridge collapse could cut a crucial link of the network completely) and time dimensions (i.e. road maintenance could finish in days, while the I-35W bridge required more than one year to rebuild). Depending on the level of disturbance, travelers have to explore the network and adjust their travel pattern accordingly. A good understanding of this process is crucial for traffic management and the design of mitigation schemes. Moreover, findings of behavioral effects could have significant implications for travel demand modeling, especially day-to-day travel demand.

However, empirical studies of traffic and behavioral effects after major network disruptions caused by these incidents are limited. Researchers are more likely to focus on the supply side and address the network reliability issue. For example, Chang and Nojima (2001) investigate the post-disaster transportation system performance after the 1989 Loma Prieta, 1994 Northridge, and 1995 Kobe earthquakes, using measures based on length of network open, total and areal accessibility. Other researchers adopt a normative paradigm and investigate the optimal traffic regulation strategy after a major disaster (e.g., Sumalee and Kurauchi, 2006). Travel demand is simplified in these models and travelers are assumed to follow either a User Equilibrium (UE) assumption or instructions from transportation agencies.

The UE assumption cannot capture the day-to-day traffic evolution after a major network disruption. Clegg (2007) shows that a capacity reduction due to road construction generated an initial "over-reaction" effect followed by a "settling down" effect, using license plate match data from the city of York, England. Oscillation of overall traffic and individual route choice are reported. However, they also report that plate-matching is error-prone and more research is required to generate convincing results. Cairnes and Goodwin (2002) investigate 70 case studies of road capacity reduction and conclude that although people changed mode, consolidated trips for different purposes, and visited alternative destinations in response to network degradation, "changing route and changing journey time seem to be the most universal". They also indicate that travelers are very adaptive and "wide-spread, long-term" disruption is rare. They argue travel behavior was conditioned on new experience instead of past history. Their study, however, is more qualitative rather than quantitative.

In contrast, Hunt et al. (2002) evaluate travelers' responses to a 14 month long closure of the Center Street Bridge in the city of Calgary, Alberta, Canada, based on both traffic counts and results from a telephone survey. A minor drop (4.4\%) in total daily trips was reported and $39 \%$ of respondents left home early. Their traffic count data include only observations from two days, in May 1999 and May 2000, respectively. The limited data prevent them from drawing statistically significant conclusions. Moreover, the economic and social background of drivers may change significantly over a year, preventing them from establishing any convincing causal effects. Nevertheless, their findings were echoed by Dahlgren (2002) who studied travel behavior changes after the reopening of I-880 in Oakland, California ten years after it was destroyed by the Loma Prieta earthquake in 1989. This research also found the popularity of route and departure time changes, and a minor but detectable reduction in travel demand due to mode changes and cancellation of trips.

Giuliano and Golob (1998) and Wesemann et al. (1996) provide a comprehensive study of traffic and behavioral responses after the 1994 Northridge Earthquake in metropolitan Los Angeles, California. However, earthquakes strike the entire network of the affected region, generating greater consequences than single-point disruptions such as bridge collapses. The day-to-day evolution in traffic pattern after bridge collapse is also different from evacuation scenarios such as those during the Hurricane Katrina and Rita (Wolshon et al., 2006), which aim at moving affected population to a limited number of destinations as soon as possible.

Thus, although significant efforts have been made to explore how travelers immediately respond to network disruptions, a comprehensive study focusing on how overall traffic and individual travel patterns vary over time has not yet been reported. Therefore, this research explores the traffic and behavioral effects over time after a major network disruption, using data from both traffic detectors and a survey. Findings from this study could inform the day-to-day modeling of travel demand.

\section{Evolution in aggregate travel demand}

After the I-35W bridge collapse, many travelers found alternative routes for their trips, both because of road or ramp closings and because of deteriorating traffic conditions on their normal route due to traffic reallocation across the network. As evidence of the traffic reallocation process, we note the extreme hike in the number of vehicle trips on Minnesota Highway 280 and the I-94 bridge crossing the Mississippi River. This was the primary alternative route detour recommended by 
Minnesota Department of Transportation (MnDOT). The average daily traffic on both directions of Minnesota Highway 280 increased from 25,000 trips in August to about 64,000 in October, while trips crossing the I-94 Mississippi River bridge increased $26.36 \%$ during the same time period (see statistics in Table 3 ).

After the bridge collapse, a series of projects were implemented to add capacity and reduce bottlenecks. For example, an additional lane was added in each direction of I-94 between I-35W and Mn 280 by reducing or eliminating shoulders and restriping the road to provide narrower lanes. Mn 280, which had been a high-speed mostly limited access route with two traffic signals, was converted to a freeway by closing several access points and reconstructing several interchange on and off-ramps.

Most of these projects were finished by the middle of August 2007, while travelers were still exploring the network and adjusting their travel pattern. By October, traffic flow became relatively stable. Wardrop's first principle (Wardrop, 1952) states that in equilibrium, "the journey times in all routes actually used are equal and less than those which would be experienced by a single vehicle on any unused route". While this ideal equilibrium is never reached, since total demand varies from day-to-day and drivers have imperfect information, it is approached. Duration of this re-equilibration process may extend from several days (Clegg, 2007) to one year (Hunt et al., 2002) depending on context, and in models has usually been assumed without solid justification. Actually, it is very difficult to verify such equilibrium from the path travel time of each origin-destination pair because of the heterogeneity of route choice criteria among the population, perception error, suboptimal behavior, and ever-changing network conditions. Instead, in this paper, traffic flow is used as a surrogate indicator, a common practice in evaluating traffic assignment results. The Root Mean Square Error (RMSE), which measures the level of deviation over time, is employed to measure the overall change of traffic. Traffic counts of 24 freeway stations, including major freeway sections within the affected zone defined by the Minnesota Department of Transportation and all freeway sections crossing the Mississippi River (locations are indicated in Fig. 1), were used to measure how significantly traffic varied over time. Given traffic flow of two time periods, $\left\{f_{t, 1}, f_{t, 2}, \ldots, f_{t, n}\right\}$ and $\left\{f_{t+1,1}, f_{t+1,2}, \ldots, f_{t+1, n}\right\}$, RMSE is defined as

$$
\operatorname{RMSE}(t+1)=\frac{\sqrt{\frac{\sum_{i=1}^{n}\left(f_{t+1, i}-f_{t, i}\right)^{2}}{N-1}}}{\bar{f}_{t+1}}
$$

Freeway Stations Used in Measuring Equilibration
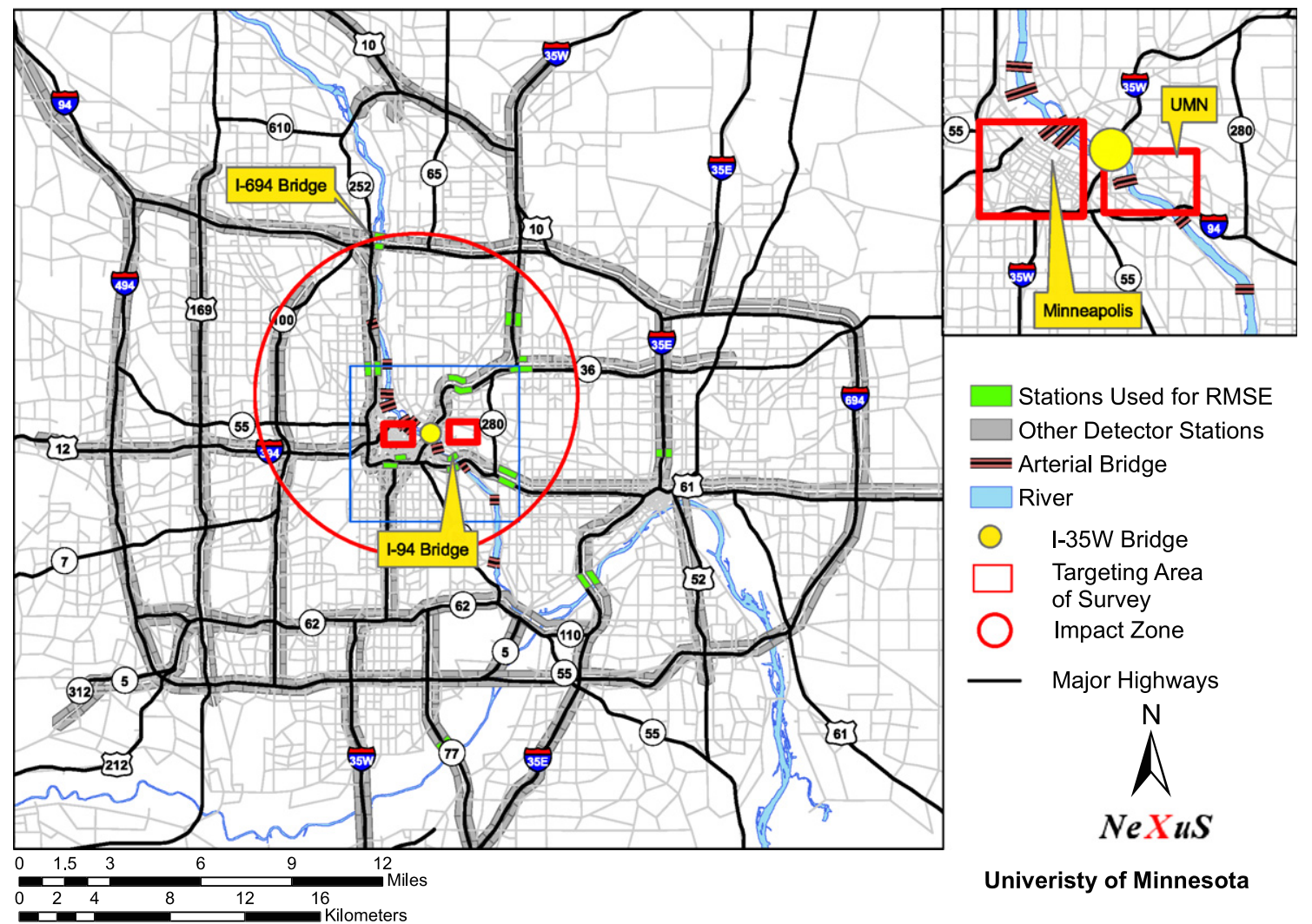

Stations Used for RMSE

Other Detector Stations

E Arterial Bridge

$\square$ River

I-35W Bridge

Targeting Area

of Survey

Impact Zone

Major Highways

$\mathrm{N}$

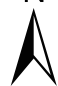

$\mathrm{NeXuS}$

Univeristy of Minnesota

Fig. 1. Traffic stations used for capturing the equilibration process. 
where $\left\{f_{t, 1}, f_{t, 2}, \ldots, f_{t, n}\right\}$ and $\left\{f_{t+1,1}, f_{t+1,2}, \ldots, f_{t+1, n}\right\}$ are average daily traffic counts within a week (Monday to Friday) at station $i$ during time period $t$ and $t+1$, respectively. It has been found that trips such as grocery shopping, visiting friends are often repeated on a weekly cycle (Clegg, 2007). Therefore, weekly average traffic counts are adopted here to avoid volatility caused by within-week effects.

RMSEs over time from both 2006 and 2007 are summarized in Fig. 2. The exaggerated increase of RMSE in August 2007 suggests that traffic patterns varied significantly immediately after the bridge collapse. Then value of RMSE decreased over the next few weeks, suggesting the network was approaching a new equilibrium. The RMSE fell within the range of normal month-to-month variation in November, implying that a new traffic pattern was established by the end of October. In order to evaluate the convergence with robust statistics, a $t$-test was conducted on the normalized weekly (Monday to Friday) average traffic. The difference introduced by locations is ruled out by normalized weekly average traffic with two-year average during the study period (June to November), while the monthly and seasonal variations are controlled by comparing 2007 and 2006 data. If 0.1 is used as the critical value, the difference in normalized weekly traffic counts in 2007 are not statistically significant compared to that of 2006 after the second week of September, which is consistent with conclusion about the length of this re-equlibration process drawn from the RMSE measure.

Although the traffic pattern on the freeway system near I-35W bridge exhibited a detectable transient state, the overall traffic demand did not change much after the bridge collapsed. Fig. 3 summarizes the on-ramp daily traffic counts from the same time period during 2006 and 2007. We only show on-ramp data here because on-ramp detectors are better maintained compared to off-ramp detectors due to their role in ramp meter control. Systematic bias could be observed between 2006 and 2007, due to absence of some detectors. However, it still indicates how overall travel demand evolved during the period after the bridge collapse. A regression is built to test if the overall travel demand across the Twin Cities area has changed due to the bridge collapse, with other confounding factors controlled. The model is as follows:

$$
y_{\text {on } \text { ramp }, t}=\beta_{0}+\beta_{1} I_{y}+\beta_{2} I_{I-35}+\beta_{3} I_{\text {Mon }}+\cdots+\beta_{8} I_{\text {Sat }}+\beta_{9} I_{\text {Aug }}+\beta_{10} I_{\text {sep }}+\varepsilon
$$

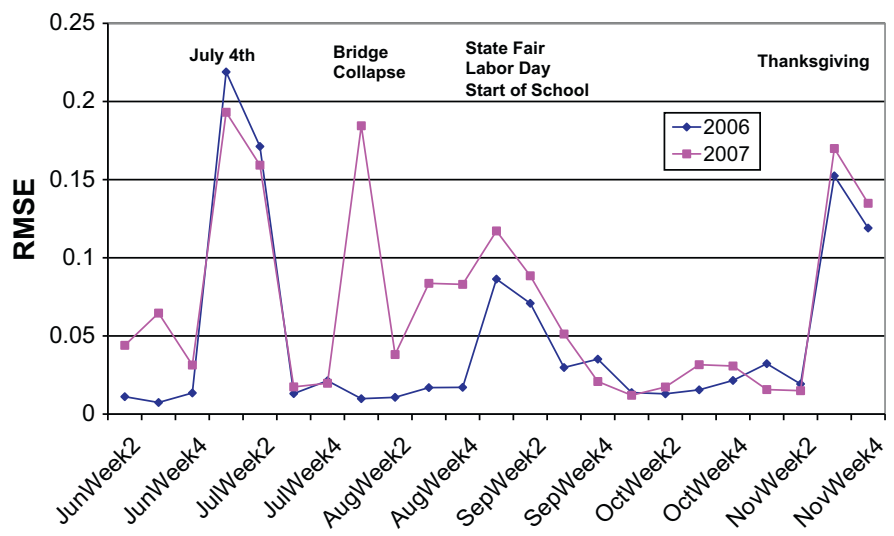

Fig. 2. Weekly changes of traffic counts measured by the Root Mean Square Error, traffic volatility returned to normal “equilibrium” levels by mid-October.

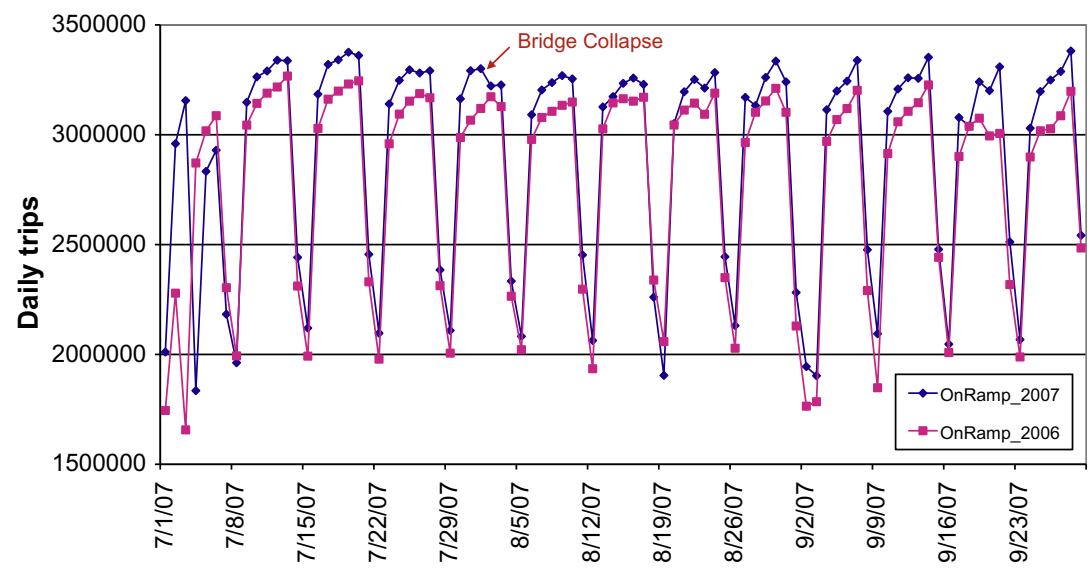

Fig. 3. Estimated daily trips on the freeway system measured by on and off-ramp counts, trips in 2007 generally exceed trips in 2006 , except for the week after the Bridge collapse. 
where $y_{t}$ is the demand captured by on-ramp loop-detectors, which is a function of dummy variables for the year $\left(I_{y}\right)$, day of the week ( $I_{\text {Mon }}$ to $\left.I_{S a t}\right)$, month $\left(I_{A u g}\right.$ and $\left.I_{S e p}\right)$ and a dummy variable indicating the time period after the bridge collapse $\left(I_{I-35}\right)$. The results are summarized in Table 1 . Although the negative sign for the bridge collapse dummy variable is consistent with the hypothesis that the collapse reduced demand, it is not statistically significant. The month did not play a significant role either. All other independent variables are statistically significant, showing important yearly and weekly variance in travel demand. This is consistent with results obtained by regressing total daily traffic counts at all freeway main-lane stations on the same set of independent variables (summarized in Table 2). The total freeway traffic increase after the bridge collapse may be due to detour travel, it is, however, insignificant. Day of the week is most important factor, and the $R^{2}$ is 0.90 , indicating that the model captures most day-to-day variation in freeway traffic. The insignificance of the bridge collapse on total travel demand could be explained by the size (most trips occurred outside of the impacted area defined by MnDOT) and the redundancy (people could easily find detour routes and other destinations for their needs) of the network. This robustness of total travel demand is consistent with previous research (Hunt et al., 2002) and survey result, which will be discussed later.

Total travel demand alone cannot capture the complexity in travel demand, especially losses people suffered when maintaining similar demand level on a degraded network. On a saturated network (which is common in large metropolitan areas, including the Twin Cities), small increases in traffic could significantly increase the level of delay. Therefore, travelers have to either wait longer in the queue, or explore the redundant capacity in the off-peak period by leaving earlier or later. And this shift in demand could result in new congestion in previous "off-peak period" as the "peak period" spreads. Fig. 4 summarizes the total freeway Vehicle Kilometers of Travel (VKT) and Vehicle Hours of Travel (VHT) on the third Wednesday of each month during 2006 and 2007. Although VKT remains flat after the bridge collapse, VHT increases. The average speed across the network (the ratio between VKT and VHT) decreased significantly after the bridge collapse, implying a higher congestion level on the network. The largest drop in average speed was observed on August 2nd, 2007, the day after the bridge collapse, before any mitigation projects were implemented and before travelers could fully adapt to the degraded network.

If we focus on the network near the I-35W bridge, travel patterns exhibited more significant changes. Table 3 summarizes daily trips on all bridges crossing the Mississippi River in the region (positions of these bridges are indicated in Fig. 1). The arterial traffic counts after the bridge collapse were collected by the City of Minneapolis on two selected days of late September and early October. The data before the bridge collapse were AADT estimated every two years by the City of Minneapolis and MnDOT. The freeway data are from the loop-detectors on two days which are close to when the observations on

Table 1

Regression on daily travel demand measured by all on-ramp loop-detectors.

\begin{tabular}{llc}
\hline & Coefficient & $t$ Stat \\
\hline Intercept & $2,116,765$ & $27.41^{* * *}$ \\
Year = 2007 & 156,044 & $1.96^{* *}$ \\
Collapse & $-57,568$ & -0.59 \\
August & 36,450 & 0.49 \\
September & $-23,943$ & -0.32 \\
Monday & 300,685 & $3.58^{* * *}$ \\
Tuesday & 832,817 & $9.92^{* * *}$ \\
Wednesday & 992,530 & $11.54^{* * *}$ \\
Thursday & 991,477 & $11.79^{* * *}$ \\
Friday & $1,022,360$ & $12.16^{* * *}$ \\
Saturday & 607,372 & $7.23^{* * *}$ \\
\hline
\end{tabular}

${ }^{* * * *}$ Statistically significant at $5 \%$ level.
Statistically significant at $1 \%$ level.

Table 2

Regression on daily demand captured by all main-lane traffic stations.

\begin{tabular}{llc}
\hline & Coefficient & $t$ Stat \\
\hline Intercept & $31,469,651$ & $65.28^{* * *}$ \\
Year = 2007 & 274,628 & 0.56 \\
Collapse & 214,431 & 0.35 \\
August & $-94,374$ & -0.21 \\
September & $-1,499,443$ & $-3.25^{* * *}$ \\
Monday & $-3,834,131$ & $-7.37^{* * *}$ \\
Tuesday & $6,952,930$ & $13.23^{* * *}$ \\
Wednesday & $9,376,140$ & $17.64^{* * *}$ \\
Thursday & $10,032,068$ & $18.89^{* * *}$ \\
Friday & $10,252,360$ & $19.50^{* * *}$ \\
Saturday & $11,159,069$ & $21.25^{* * *}$ \\
\hline
\end{tabular}

Statistically significant at $1 \%$ level. 


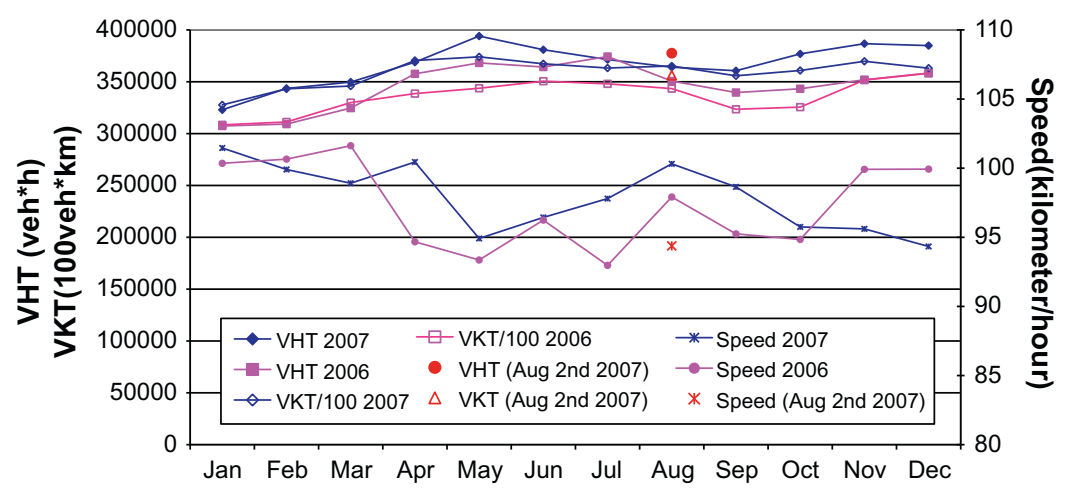

Fig. 4. Freeway Vehicle Kilometers of Travel (VKT) and Vehicle Hours of Travel (VHT) and average speed, estimated on the third Wednesday of each month. Total travel (both VKT and VHT) was generally higher in 2007 than 2006, speeds varied, though August 2nd was considerably slower as many drivers were on unfamiliar route in a dis-equilibrium condition.

Table 3

Traffic count on bridges crossing Mississippi River.

\begin{tabular}{llllr}
\hline Bridge & Before & After & Increase & Percentage \\
\hline Camdon St & 8748 & N/A & & \\
Broad St & 20,931 & N/A & & 2616 \\
Lowry St & 16,296 & N/A & 12,377 & 36.88 \\
Plymouth St & 11,226 & 13,842 & 8120 & 25.94 \\
Hennepin Ave & 33,559 & 45,936 & 6581 & 24.06 \\
3rd Ave & 31,303 & 39,423 & 11,228 & 54.21 \\
10th St & 27,356 & 33,937 & 3261 & 33.28 \\
Washington St & 20,713 & 31,941 & 1072 & 5.84 \\
Franklin Ave & 9800 & 13,061 & 8219 & 5.12 \\
Ford Bridge & 18,354 & 19,426 & 41,058 & 26.36 \\
I-694 & 160,426 & 168,645 & 781 & 0.90 \\
I-94 & 155,771 & 196,829 & -1292 & -4.48 \\
I-35E & 87,251 & 88,032 & $-140,000$ & -100.00 \\
TH-55 & 28,826 & 27,534 & 45,255 & 29.71 \\
I-35W & 140,000 & 0 & $-91,234$ & -15.94 \\
Arterial total & 152,311 & 197,566 & $-45,979$ & -6.35 \\
Freeway total & 572,274 & 481,040 & 678,606 & \\
Total & 724,585 & & & \\
\hline
\end{tabular}

arterials were made. About one-third of the traffic switched to arterials to cross the river, while one third were diverted to freeway alternatives, primarily the I-94 bridge. However, one-third of previous trips using the I-35W bridge disappeared, which may be due to changes in destination and trip consolidation, and to a lesser extent changes in mode. These findings are consistent with previous research (Goodwin, 1977; Giuliano and Golob, 1998) and survey results to be discussed.

\section{Impacts for mode choice}

Local media and practitioners expected immediate after the bridge collapse that the extra congestion following bridge collapse would persuade a significant amount of travelers to switch to public transit. Conclusions about the impacts on transit ridership due to network disruptions could have important implications for traffic management. In the literature, travelers show great resistance to changing mode (Hunt et al., 2002; Giuliano and Golob, 1998). As part of the mitigation plan in response to the bridge collapse, Metro Transit, the primary public transit service provider at the Twin Cities, enhanced their service by adding new buses and expanding capacity in park-and-ride lots. The monthly bus ridership was collected at the fare box and documented by Metro Transit. Fig. 4 summarizes the monthly total trips during 2006 and 2007 , on all routes and on those routes crossing the Mississippi River, respectively. In order to detect the effects of the bridge collapse, a regression is built as follows:

$$
y_{t}=\beta_{0}+\beta_{1} D_{t}+\beta_{2} I_{y}+\beta_{3} V K T_{t}+\beta I_{I-35}+\varepsilon
$$

where $y_{t}$ is the monthly ridership, which is a function of the number of work days of the month $\left(D_{t}\right)$, dummy variables for the year $\left(I_{y}\right)$, total Vehicle Kilometers Travel in the month $\left(V K T_{t}\right)$ and a dummy variable indicating the time period after the bridge collapse $\left(I_{I-35}\right)$. Table 4 summarizes the results and an $R^{2}$ value of 0.57 was obtained. The number of work days is statistically significant and positively correlated with the monthly ridership. This is consistent with the fact that $48.3 \%$ of 
Table 4

Regression on monthly transit ridership.

\begin{tabular}{lcl}
\hline & Coefficient & $t$ Stat \\
\hline Intercept & $1,759,581$ & $1.85^{*}$ \\
WorkDays & 122,085 & 2.44 \\
$2007 / 2006$ & 27,159 & 0.22 \\
VKT (million) & 844.38 & 0.92 \\
After collaspe & 349,697 & $2.50^{* *}$ \\
\hline
\end{tabular}

Statistically significant at $10 \%$ level.

* Statistically significant at 5\% level.

total public transit trips are commute trips (home-based work, home-based work-related, home-based school and nonhome-based work) in the Twin Cities (seven county area) according to the 2000 Travel Behavior Inventory (TBI) conducted by the Metropolitan Council. The impact of the bridge collapse is statistically significant, leading to a $6.6 \%$ increase in monthly ridership according to the regression model. The year-to-year effect is positive, but not statistically significant. The freeway VKT did not play a significant role either, suggesting different patterns exist for transit usage and freeway traffic. Since except for expresses, most buses exclusively use arterial roads, transit is more of a substitute for arterial travel than freeway travel. Similar results are obtained by regressing the total number of trips on all crossing-river routes, although the magnitude of impacts due to the bridge collapse is larger (7.4\%) according to the coefficients. However, bus riders on these routes do not necessarily cross the river. Moreover, public transit trips represent only $2.3 \%$ of total trips in the seven county area according to the 2000 TBI. Therefore, the effects of such increases in transit ridership are limited and probably undetectable from traffic counts. The limited increase in transit ridership suggests that it is impractical to expect significant changes in mode share under future scenarios.

\section{Behavioral reactions}

Travel demand emerges from individual decisions. In order to better understand traffic evolution and the equilibration process after the bridge collapse, it is crucial to explore individual travel choices in the wake of major transportation network disruption. A mail-in survey was conducted by the University of Minnesota, during September 2007. A copy of the questionnaire is attached in Appendix A, which includes four parts: questions about demographic information, self-evaluation of the impacts on general travel patterns, travel choices regarding morning commute, and four maps on which respondents were asked to draw their commute routes. In order to keep the survey salient, demographic questions include only gender and family size, two factors which are likely to influence travel patterns. However, the residential and work locations, which may link survey data with other data resources such as metropolitan planning models and thus inform route choice decisions, were explicitly asked. Respondents were asked to assess whether they were affected by the bridge collapse in general, and how they reacted (e.g did they cancel trips, avoid certain destinations, change departure time, mode, and/or route, engage in more telecommuting, etc.). More specifically, questions were asked about their morning commute pattern, including the departure time, the arrival time, travel mode and route choice during four phases: before the bridge collapse, the morning after the bridge collapse, the following weeks, and current status (at the time of the survey). Answers to these questions illustrate how travelers adapted to network changes and inform the analysis about the underlying criteria for making these decisions. Moreover, respondents were asked to identify their motivations for adjusting travel patterns and the resources which assisted in those decision-making processes.

Changing route is one of the most easily adopted strategies to avoid unfavorable traffic conditions (as shown in the survey results). However, it is very difficult for respondents to clearly and completely describe their commute routes in limited words. Consequently it is challenging for researchers to correctly understand information conveyed through those words and replicate the routes in analysis. Therefore, maps were adopted in this survey for drivers to communicate route information. Four identical maps of the surface road network in the Twin Cities were included in the survey and respondents were asked to draw their commute route during the four time periods previously defined. The maps included freeways, arterials, and major streets, and were detailed enough to show major route changes. Respondents were asked to draw all routes they frequently used during the four time periods. These routes, together with the reported residential and work locations, were then digitized and compared in a geographic information software package (Arc/GIS). Meanwhile, traffic data during these time periods, including both traffic counts and point speed, were collected from the loop-detector system of MnDOT, which provides a good estimate of traffic conditions experienced by respondents in their day-to-day commute.

It is crucial to conduct a pretest in survey research to rule out ambiguity and confusions in survey questions and the design of questionnaires (Hunt et al., 1982). In order to develop a quality survey within this limited time frame, many of the questions were adopted, with necessary revisions, from a previous survey study conducted by Levinson et al. (2006). We attempted an ad-hoc pretest with ten students from the Department of Civil Engineering (not involved in this project). They filled out the questionnaire. Researchers then probed these individuals for potential problems for the design of the questionnaire. Although no sign of uneasiness, confusion, and resistance were reported from our ad-hoc pretest, a more systematic pretest would be advised in future research. 
The survey was distributed in both the downtown area of the City of Minneapolis and the nearby Minneapolis campus of the University of Minnesota, Fig. 1 shows the relative locations (indicated by two red rectangles) of these two areas near the I-35W bridge (the yellow dot) and thus significantly affected by the bridge collapse. According to the 2005 Longitudinal Employment and Household Dynamics (LEHD) data, these two communities concentrated about 41.3\% of total employment $(413,939)$ within the impacted zone defined by MnDOT after the bridge collapse, which is bounded by Minnesota Highways 100, 62, and 51 and Interstate Highway 694 with a radius of 5 miles (see Fig. 1). Constrained by the amount of time and funding efforts available immediately after the bridge collapse, we concentrated resources in these two communities. Survey questionnaires were randomly handed out on streets, at bus stops, and at the exits of structured parking ramps during the workday afternoon of the first two weeks in September, 2007. A total of 1000 survey forms were handed out, and responses came in through September and October. In all, 141 usable responses were received. Data were digitized and matched with traffic data from MnDOT for further analysis.

\subsection{Characteristics of respondents}

Table 5 summarizes the basic characteristics of all respondents, while the residential and work locations are illustrated in Fig. 5. Among the 141 respondents, $61.7 \%$ were female, which is significantly higher than the national average value (49.8\% according to 2000 Census). The average household size is 2.80 , which is slightly higher than the average value in Minnesota, 2.52, according to 2000 Census. Considering the limited sample size, these biases should be acceptable. More importantly, the geographic distribution of our respondents is well-dispersed across the Twin Cities area as shown in Fig. 5, which suggests that they are representative of the impacts on travel patterns of the bridge collapse for individuals who work in areas near the bridge.

The respondents covered the full spectrum of travel modes. Single drivers (56.03\%) represent the largest share of travel mode. Considering the strict parking restrictions and high level of service of public transit in the two survey areas, it is not surprising to see a large share of bus riders (26.95\%). According to the 2000 Census, $25 \%$ of daily commuting trips to downtown Minneapolis are made through public transit, and according to the 2000/01 Travel Behavior Inventory conducted by the Metropolitan Council, 44\% of peak hour commuting trips are by transit (Levinson and Krizek, 2008), while transit carries

Table 5

General characteristics of survey respondents.

\begin{tabular}{|c|c|c|c|}
\hline & & Counts & Percentage \\
\hline \multirow[t]{3}{*}{ Gender } & Female & 87 & 61.70 \\
\hline & Male & 48 & 34.04 \\
\hline & $\mathrm{N} / \mathrm{A}$ & 6 & 4.26 \\
\hline \multirow[t]{8}{*}{ Household size } & 1 & 17 & 12.06 \\
\hline & 2 & 50 & 35.46 \\
\hline & 3 & 22 & 15.60 \\
\hline & 4 & 30 & 21.28 \\
\hline & 5 & 10 & 7.09 \\
\hline & $\geqslant 6$ & 6 & 4.26 \\
\hline & $\mathrm{N} / \mathrm{A}$ & 6 & 4.26 \\
\hline & Average & 2.8 & \\
\hline \multirow[t]{6}{*}{ No. of children (age $0-5$ ) } & 0 & 105 & 74.47 \\
\hline & 1 & 16 & 11.35 \\
\hline & 2 & 6 & 4.26 \\
\hline & $\geqslant 3$ & 1 & 0.71 \\
\hline & $\mathrm{N} / \mathrm{A}$ & 19 & 13.48 \\
\hline & Average & 0.19 & \\
\hline \multirow[t]{6}{*}{ No. of children (age 6-16) } & 0 & 89 & 63.12 \\
\hline & 1 & 15 & 10.64 \\
\hline & 2 & 15 & 10.64 \\
\hline & $\geqslant 3$ & 7 & 4.96 \\
\hline & $\mathrm{N} / \mathrm{A}$ & 15 & 10.64 \\
\hline & Average & 0.49 & \\
\hline \multirow[t]{7}{*}{ Commute mode } & Drive alone & 79 & 56.03 \\
\hline & Carpool/vanpool & 10 & 7.09 \\
\hline & Bus & 38 & 26.95 \\
\hline & Bike & 2 & 1.42 \\
\hline & Walk & 2 & 1.42 \\
\hline & Park and Ride & 6 & 4.26 \\
\hline & $\mathrm{N} / \mathrm{A}$ & 4 & 2.84 \\
\hline \multirow[t]{3}{*}{ Flexibility in work schedule } & Yes & 77 & 54.6 \\
\hline & No & 56 & 39.7 \\
\hline & $\mathrm{N} / \mathrm{A}$ & 8 & 5.7 \\
\hline
\end{tabular}




\section{Origin and Destination Distribution of Survey Respondents}

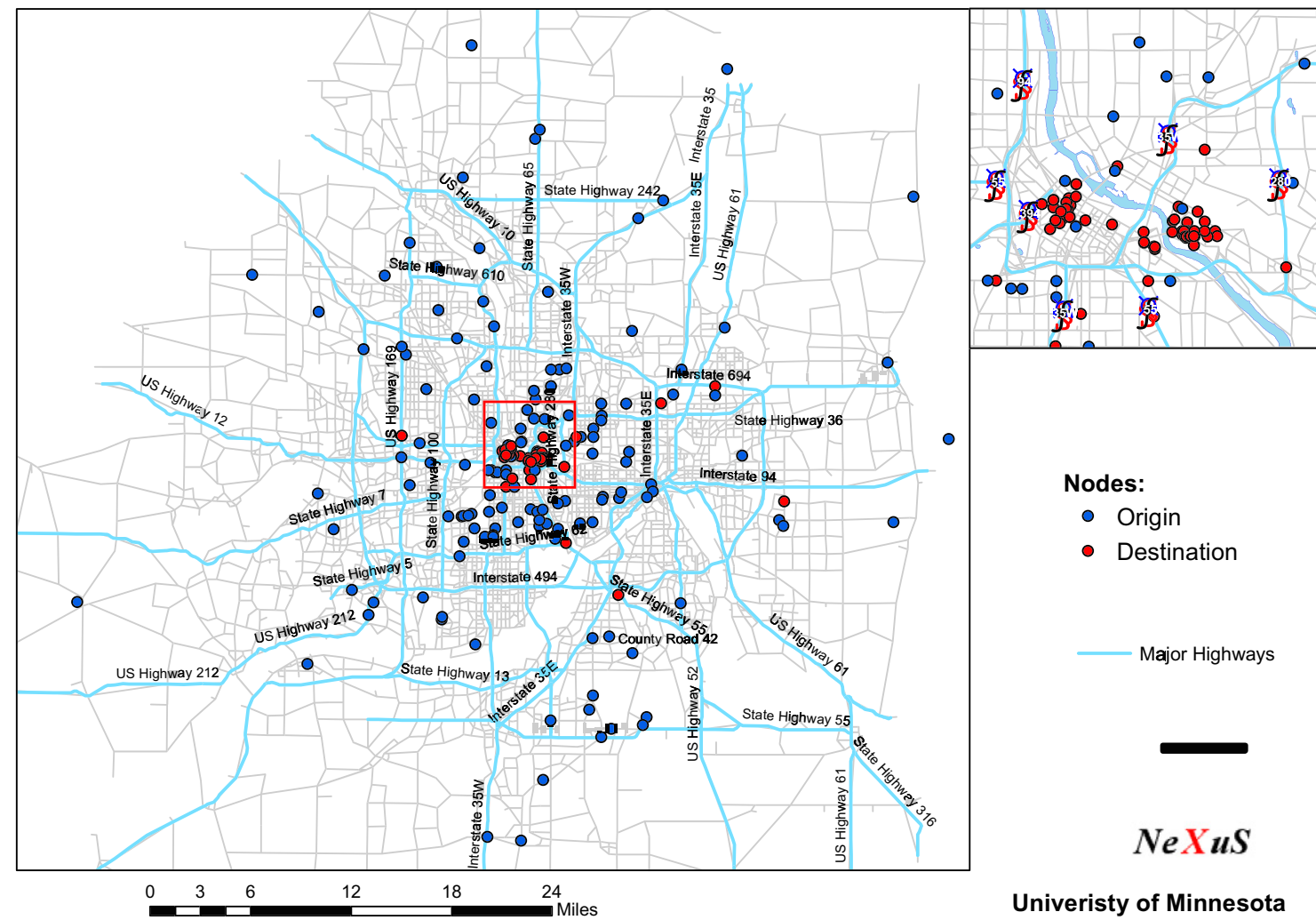

Fig. 5. Work and residential locations of survey respondents.

$24 \%$ of all trips to campus according to the University of Minnesota, Parking and Transportation Service. From the survey, bus riders (including park-and-ride) represent $20.2 \%$ of respondents commuting to the University of Minnesota campus and $48 \%$ of those commuting to downtown Minneapolis. The share of transit riders to downtown in our survey is significantly higher than the daily average, but close to the peak hour value. The diurnal graph of departure and arrival time shows $84 \%$ of respondents left home during the morning peak period (6:00 am-9:00 am). Therefore, our survey result is roughly consistent with overall mode shares among commuters. Regarding the flexibility of work schedules, $54.6 \%$ of respondents responded positively, while $39.7 \%$ stated that they had no flexibility in work schedule.

\subsection{Changes in general commute patterns after bridge collapse}

Table 6 illustrates the impact of the I-35W bridge collapse on general travel patterns and reactions among respondents. Among 141 respondents, 55\% claimed that they were affected by this incident. The most widely adopted adjustments in travel pattern is to change the departure time (75\% among those affected) and to change route ( $73 \%$ among those affected). About $61 \%$ of those respondents categorized as affected chose alternative destinations for their activities, while some chose an alternative mode (6\%) or telecommuting (9\%). These adjustments in travel pattern are not mutually exclusive, thus travelers could make multiple changes simultaneously. Observations from the survey are consistent with our assumptions that

Table 6

Reactions to the bridge collapse by mode.

\begin{tabular}{|c|c|c|c|c|c|c|c|c|}
\hline & Total & Affected (\%) & Cancel trips (\%) & Avoid dest. (\%) & Change DT (\%) & Mode (\%) & Route (\%) & Work at home (\%) \\
\hline Total & 141 & 54.61 & 7.80 & 33.33 & 41.13 & 3.55 & 39.72 & 4.96 \\
\hline Affected & 77 & & 14.29 & 61.04 & 75.32 & 6.49 & 72.73 & 9.09 \\
\hline Single driver & 79 & 65.82 & 8.86 & 39.24 & 51.90 & 3.80 & 50.63 & 7.59 \\
\hline Carpooler & 10 & 60.00 & 10.00 & 20.00 & 30.00 & 10.00 & 60.00 & 0.00 \\
\hline Bus rider & 38 & 42.11 & 2.63 & 28.95 & 28.95 & 0.00 & 15.79 & 0.00 \\
\hline Bicyclist & 2 & 50.00 & 50.00 & 50.00 & 50.00 & 0.00 & 50.00 & 0.00 \\
\hline Walk & 2 & 0.00 & & & & & & \\
\hline
\end{tabular}


the departure time and travel route are the easiest adjustments travelers can make in the wake of a major sudden network disruption.

Individuals resist changes in travel mode because it involves major shifts in lifestyle and is constrained by other factors such as service availability and car ownership. However, better coverage and higher frequency public transit encourages people to ride buses. For example, two respondents indicated in comments that the improved express bus lines and discounted annual bus pass helped to persuade them to ride the bus.

Although a high percentage of respondents reported they chose alternative destinations to satisfy their needs, this number is more likely to represent non-commute trips such as visiting friends or going shopping. Few respondents reacted by increasing telecommuting (Work at home) and it is unlikely that people would make long-term adjustments such as work or residential location changes in such a short time period.

Individual choices produce trends that are consistent with observations of aggregate traffic patterns. It is not surprising to see the overall travel demand remains stable since very few people forgo trips or choose telecommuting. Furthermore, route choice and departure time decisions only affect the distribution of trips. They do not influence aggregate travel demand. Nevertheless, the reaction of choosing alternative destinations to satisfy their needs helps to explain the drop in the number of crossing-river trips.

If we evaluate reactions by mode, $66 \%$ of single drivers and $60 \%$ of carpoolers claimed to be influenced by the bridge collapse, the highest among all modes. It is not surprising that the percentage of bus riders who were affected was much lower (42\%), since very few routes used this bridge before it collapsed. Notably, buses could benefit from driving on hard shoulders in the peak hours prior to the bridge collapse, but after the widening and restriping of I-94, the hard shoulders became regular travel lanes, simultaneously increasing overall speed but decreasing the speed advantage that buses possessed. Single drivers adapted to the network disruption by changing routes (51\%) and departure time (52\%), and less frequently destinations (39\%). However, carpoolers were more likely to change routes (60\%) while less likely to change departure time (30\%) or destinations (20\%) according to the survey. Carpoolers may have less flexibility in departure time and destination in order to achieve coordination. Constrained by the service provided, bus riders are unlikely to change route (16\% according to the survey). Shift rates in destination and departure time are $29 \%$ for both. Due to limited number of observations, the trends in bicyclist are not representative.

\subsection{Shifts in morning commute}

Table 7 summarizes the travel mode, the departure time, and the arrival time of morning commute over time illustrating major changes in wake of the bridge collapse. As previously indicated, the mode share is very stable despite the disturbance on the network and no significant changes were detected. In contrast, a significant share of respondents (27.7\%) indicated

Table 7

Changes in commute travel pattern.

\begin{tabular}{|c|c|c|c|c|}
\hline & July & Aug 2nd & Weeks ater & End of Sep. \\
\hline \multicolumn{5}{|l|}{ Travel mode (\%) } \\
\hline Drive alone & 56.03 & 51.77 & 54.61 & 54.61 \\
\hline Carpool/vanpool & 7.09 & 7.09 & 6.38 & 7.09 \\
\hline Bus & 26.95 & 26.24 & 26.24 & 27.66 \\
\hline Bike & 1.42 & 2.13 & 2.13 & 1.42 \\
\hline Walk & 1.42 & 1.42 & 1.42 & 2.13 \\
\hline Park and Ride & 4.26 & 4.26 & 4.26 & 4.96 \\
\hline $\mathrm{N} / \mathrm{A}$ & 2.84 & 7.09 & 4.96 & 2.13 \\
\hline \multicolumn{5}{|l|}{ Departure time } \\
\hline Depart later (\%) & & 4.3 & 7.1 & 9.9 \\
\hline No change (\%) & & 58.9 & 66.0 & 68.1 \\
\hline Depart earlier (\%) & & 27.7 & 20.6 & 17.7 \\
\hline $\mathrm{N} / \mathrm{A}$ & & 9.2 & 6.4 & 4.3 \\
\hline Average advances in depature (min) & & 16.5 & 13.4 & 19.7 \\
\hline Average delays in depature (min) & & 61.7 & 50.5 & 40.4 \\
\hline \multicolumn{5}{|l|}{ Arrival time } \\
\hline Arrive later (\%) & & 21.3 & 20.6 & 22.0 \\
\hline No change (\%) & & 60.3 & 65.2 & 63.1 \\
\hline Arrive earlier (\%) & & 9.9 & 5.7 & 7.1 \\
\hline $\mathrm{N} / \mathrm{A}$ & & 8.5 & 8.5 & 7.8 \\
\hline Average advances in arrival (min) & & 15.00 & 12.00 & 24.89 \\
\hline Average delays in arrival (min) & & 28.00 & 31.00 & 30.35 \\
\hline \multicolumn{5}{|l|}{ Commuting time } \\
\hline Average (min) & 35.62 & 40.18 & 38.63 & 38.74 \\
\hline $\begin{array}{l}\text { Changes compared } \\
\text { to the length in July (min) }\end{array}$ & & 5.13 & 3.21 & 3.20 \\
\hline
\end{tabular}


that they departed earlier than usual on the day after the bridge collapse, and the percentage dropped slowly thereafter (17.7\% by the end of September). Only 8 respondents (5.7\%) cancelled their commute trips on August 2nd.

However, a few travelers (4.3\% on August 2nd) chose to depart later than usual and that percentage increased slightly since then. Considering the percentage of respondents with flexibility in work schedule (54.6\%), many travelers may choose to postpone their morning commute to avoid the congestion in peak hours. However, travelers still prefer early departure compared to late departure, showing a preference for a standard work schedule.

Similarly, a relatively constant share of respondents (about 22.0\%) arrived later than their usual schedule before the bridge collapse, while fewer then $10 \%$ arrived earlier to work. Later departures increased over the two month period compared to pre-collapse, while earlier departures (compared to pre-collapse) declined over this period.

The individual commuting time can be derived by comparing the self-reported departure time and arrival time. As indicated in Table 7, the average commuting time to work before the bridge collapse was $35.62 \mathrm{~min}$, which is well above the average travel time to work for the City of Minneapolis (24 min for home-based work trips according to 2000 Metropolitan Council TBI data).

On August 2nd, average commuting time jumped to $40.18 \mathrm{~min}$, which resulted from the traffic restrictions imposed to facilitate the rescue work and unfamiliarity with the new network conditions among commuters on the day following the bridge collapse. The average travel time reduced to about $38 \mathrm{~min}$ on average and remained constant since then. The disturbance caused by the bridge collapse thus cost each traveler in the survey population $3.2 \mathrm{~min}$ in the morning commute. However, the experienced delay is not evenly distributed among population. Comparing the self-reporting commute time before and after the bridge collapse (summarized in Fig. 6), most respondents (about 52.8\%) did not feel significant delay on August 2nd, while this number increased to $61.7 \%$ by the end of September. Some respondents (as many as $8.4 \%$ by the end of September) were better off because of traffic reallocation (e.g. those who use I-35W but exited upstream of the bridge, or those who benefitted from improvements to I-94 and Mn280).

\subsection{Information and motivations}

Motivations for adjusting travel patterns and information resources used are documented in Table 8 . About half of the respondents adapted themselves to the evolving network conditions to save travel time. The number of travelers who adjusted their travel behavior because of road or ramp closure peaked on August 2nd (23.4\%), while this number dropped as many roads were reopened or expanded in the following weeks. However, there are still about $13 \%$ of respondents who changed their travel pattern for reasons not listed in this survey.

People are likely to make judgements based on what they see. The day-to-day travel experience about network conditions was the primary source of information, used by two-thirds of respondents. One-third of respondents relied on radio for information, and one-fourth on television. Television, more than radio, is likely to influence the before-trip decisions. Web pages were used by about one-sixth of travelers.

Social contacts such as family members, neighbors, and co-workers were used by $13.5 \%$ of respondents as information resources. This number increased slightly after the bridge collapse, possibly reflecting more positive search efforts. However, this share returned to the original level before the bridge collapse by the end of September when a new equilibrium was established and search efforts reduced.

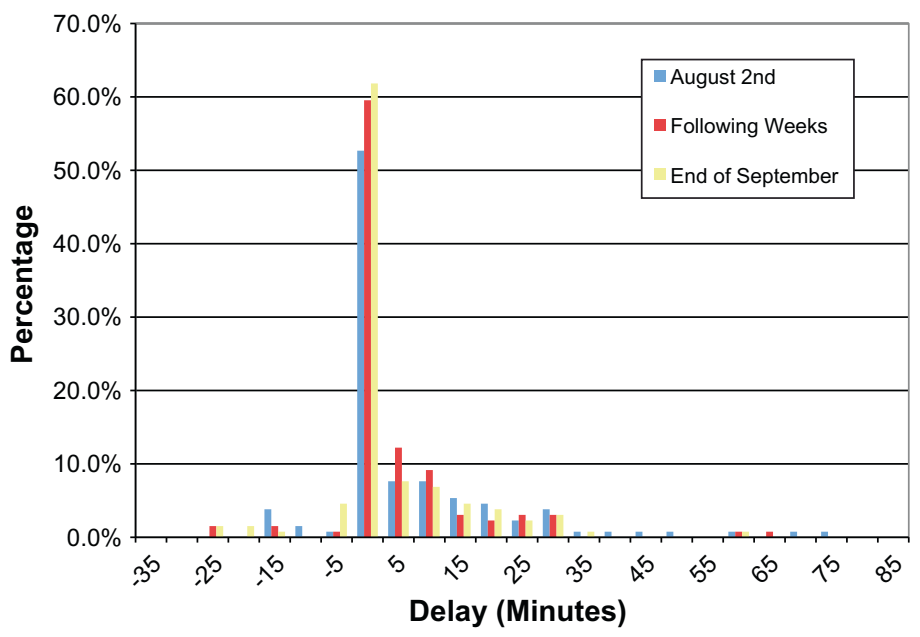

Fig. 6. Histogram of survey reported changes in travel time (after - before), most drivers saw no change, some drivers saw an increase in travel time, and a few reported a decrease in travel time. 
Table 8

Reasons for changing travel pattern and information resources assisting decision-making (\%).

\begin{tabular}{lcccc}
\hline & July & Aug 2nd & Weeks after & End of Sep. \\
\hline Motivations & & & & \\
Save travel time & 49.6 & 41.8 & 46.8 & 50.4 \\
Road or ramp closure & 12.1 & 23.4 & 19.9 & 17.7 \\
Others & 12.1 & 12.1 & 13.5 & 14.9 \\
N/A & 36.2 & 31.2 & 30.5 & 27.7 \\
Information resources & & & & \\
Experience & 64.5 & 54.6 & 61.7 & 64.5 \\
Call 511 & 0.7 & 0.7 & 0.7 & 0.7 \\
Website & 17.7 & 22.7 & 21.3 & 20.6 \\
TV & 27.0 & 29.1 & 24.8 & 24.8 \\
Radio & 34.8 & 38.3 & 35.5 & 13.5 \\
Social contacts & 13.5 & 14.9 & 16.3 & 7.1 \\
Co-workers & 5.7 & 7.1 & 8.5 & 2.1 \\
Neighbors & 1.4 & 1.4 & 2.1 & 6.4 \\
Family & 7.8 & 7.8 & 7.1 & 3.5 \\
Others & 1.4 & 2.8 & 2.1 & \\
\hline
\end{tabular}

Surprisingly, only one of all the 141 respondents stated that calling 511 helped make travel decisions. Although cellphones are readily available both at home and on route, the 511 program is apparently not widely used in Minnesota.

\subsection{Commute routes}

In order to identify any changes in travel routes, respondents were asked to draw their commute routes during four time periods: before the bridge collapse, August 2nd, the weeks following the bridge collapse, and late September when this survey was conducted. Although 141 replies were received, we were only able to identify routes choices from 60 respondents. Most bus riders did not draw the commute routes on maps. This may be because bus riders generally focus more on the location of boarding and alighting, while paying less or no attention to the route buses are actually traveling. Moreover, many people who perceived little impact from the bridge collapse simply ignored the request to draw maps because they thought this was irrelevant. This reason could also help to explain the low reporting rate among bus riders since they were much less likely to change commute route.

Usually, only one route was reported for any given time period per respondent, indicating a reluctance to frequently switch routes. However, 34 travelers reported more than one route, illustrating the exploration process. Some 60 routes were identified for the period before August 1st and the final time period, although some of them may be identical, indicating travelers switched back to their original routes. In the interim, 18 and 16 routes were reported for August 2nd and the weeks after, respectively.

\section{Conclusion}

Despite the heavy losses in life and injury, as well as the psychological shock, the collapse of I-35W bridge did not disastrously disrupt the overall traffic of Twin Cities network as initially predicted by the mass media. Travelers exhibited great flexibility in dealing with the changed traffic pattern, although some encountered more inconvenience than others. Both the survey data and traffic counts suggested that total travel demand did not significantly reduce after the network collapse, possibly because of redundant capacity provided by alternatives: The capacity of the nearby I-94 Mississippi River bridge was expanded by restriping the shoulders as an additional lane in each direction; arterial bridges sustained heavier traffic; nonpeak period capacity got better use, all of which helped to compensate for the capacity losses. However, the stability in total demand did not suggest no losses for travelers. Instead, the total travel time is clearly longer on average for those commuting to downtown or the nearby University of Minnesota. The spread of the peak period on the I-94 bridge is more strong evidence. Moreover, the rerouting process and higher level of congestion could imply losses of opportunities, which is important but subtle to detect. About one-third of all trips which had used the I-35W bridge before the tragedy no longer crossed the river, implying losses of economic benefit associated with those trips.

Apparently, the bridge collapse did not generate a large increase in public transit ridership, which is consistent with observations in previous research (Giuliano and Golob, 1998). The difficulty in promoting public transit could be due to travel inertia (Goodwin, 1977) and flexibility for family needs (e.g. pick up child at day care). However, both Dimitriou et al. (2006) and Hensher and Brewer (2002) argued that major incidents provide good opportunities for travelers to experience alternative modes, which if successful could promote their use over the long-term. Therefore, follow-up studies are needed to investigate impacts of bridge collapse on transit ridership.

Evidence from both traffic observations and survey results clearly indicated that changing routes and changing journey departure time are the most common responses to the bridge collapse. Travelers make these decisions either simultaneously or in sequence. Future research efforts are needed to disentangle them. 


\section{Appendix A}

Survey of Travel Behavioral Consequences of I-35W Bridge Collapse

Please complete the table, indicating the choice best describing your MORNING COMMUTE trip in the following time periods and draw your route(s) on the attached maps.

\begin{tabular}{|c|c|c|c|c|}
\hline & $\begin{array}{l}\text { Before I-35W } \\
\text { Bridge Collapse }\end{array}$ & $\begin{array}{l}\text { After Bridge } \\
\text { Collapse August } \\
\text { 2nd }\end{array}$ & Following Weeks & Current Status \\
\hline \multicolumn{5}{|l|}{$\begin{array}{l}\text { Departure Time: } \\
\text { (Typical time leaving home, to the } \\
\text { nearest minute) }\end{array}$} \\
\hline \multicolumn{5}{|l|}{$\begin{array}{l}\text { Arrival time: } \\
\text { (Typical time arriving at work, to } \\
\text { the nearest minute) }\end{array}$} \\
\hline \multicolumn{5}{|l|}{$\begin{array}{l}\text { Travel Mode: } \\
\text { (Please indicate the primary } \\
\text { mode of travel) } \\
\text { a) Drive alone b) Car/vanpool } \\
\text { c) Bus/Light rail d) Bicycle } \\
\text { e) Walk } \\
\text { f) Other ......... (Please } \\
\text { specify) }\end{array}$} \\
\hline $\begin{array}{l}\text { Route Choice } \\
\text { (Please draw your routes on the } \\
\text { attached maps. If you take bus or } \\
\text { LR, please indicate the route and } \\
\text { on and off stops.) }\end{array}$ & $\begin{array}{l}\text { Please mark line(s) on } \\
\text { the map } 1\end{array}$ & $\begin{array}{l}\text { Please mark line(s) on } \\
\text { the map } 2\end{array}$ & $\begin{array}{l}\text { Please mark line(s) on } \\
\text { the map } 3 \text { If more } \\
\text { than one, please } \\
\text { indicate } \boldsymbol{A L L} \text { of them. }\end{array}$ & $\begin{array}{l}\text { Please mark line(s) on } \\
\text { the map } 4\end{array}$ \\
\hline \multicolumn{5}{|l|}{$\begin{array}{l}\text { Travel Information Re- } \\
\text { sources: } \\
\text { (Which source(s) of information } \\
\text { help you make travel decisions) } \\
\text { a) Experience b) Call } 511 \\
\text { c) Website d) TV } \\
\text { e) Radio f) Co-workers } \\
\text { g) Neighbors h) Family } \\
\text { i) Others ...............(Please specify) }\end{array}$} \\
\hline $\begin{array}{l}\text { Motivation for Changes in } \\
\text { Travel Choices: } \\
\text { a) To reduce travel time } \\
\text { b) Road or ramp closed } \\
\text { c) Others .......... (Please specify) }\end{array}$ & & & & \\
\hline
\end{tabular}

Please answer the following.

Did the bridge collapse affect your travel: ( $\square \mathrm{Y} / \square \mathrm{N})$

If so, did you cancel trip(s) ( $\square \mathrm{Y} / \square \mathrm{N}$ ) avoid certain destinations ( $\square \mathrm{Y} / \square \mathrm{N}$ ) change departure time ( $\square \mathrm{Y} /$

$\square \mathrm{N})$ change mode $(\square \mathrm{Y} / \square \mathrm{N})$ change route $(\square \mathrm{Y} / \square \mathrm{N})$ work at home more frequently $(\square \mathrm{Y} / \square \mathrm{N})$

Where do you reside: (Please provide nearest cross street)

Where do you work: (Please provide nearest cross street)

Are you: $\square$ Male $\square$ Female

Do you have a flexible work schedule: $(\square \mathrm{Y} / \square \mathrm{N})$

How many people live in your houeshold: . How many children: age 0-5 _........... age 6-16

How much time savings would be required for you to change routes: ....................... Minutes

How much time savings would be required for you to change travel modes: ....... Minutes

How did you find out about the I-35W Bridge Collapse.

Please comment on the back about how you changed your travel behavior in response to the bridge collapse.

\section{References}

Cairnes, S., Atkins, S., Goodwin, P., 2002. Disappearing traffic? The story so far. In: Proceedings of the Institution of Civil Engineers, pp. 13-22.

Chang, S., Nojima, N., 2001. Measuring post-disaster transportation system performance: the 1995 Kobe earthquake in comparative perspective. Transportation Research Part A 35, 475-494.

Clegg, R., 2007. Empirical Studies on Road Traffic Response to Capacity Reduction, Transportation and Traffic Theory 2007: Papers Selected for Presentation at ISTTT17. Elsevier Science.

Dahlgren, J., January 2002. The effects of reconstruction of I-880 on travel behavior. Transportation Research Board Meeting. Washington, DC.

Dimitriou, D., Karlaftis, M., Kepaptsoglou, K., Stathopoulos, M., 2006. Public Transportation During the Athens 2004 Olympics: From Planning to Performance. Transportation Research Board.

Giuliano, G., Golob, J., 1998. Impacts of the Northridge earthquake on transit and highway use. Journal of Transportation and Statistics 1, 1-20.

Goodwin, P., 1977. Habit and hysteresis in mode choice. Urban Studies 14, 95-98.

Hensher, D., Brewer, A., 2002. Going for gold at the Sydney Olympics: how did transport perform? Transport Reviews 22, 381-399. 
Hunt, J., Brownlee, A., Stefan, K., 2002. Responses to centre street bridge closure: where the disappearing travelers went. Transportation Research Record $1807,51-58$.

Hunt, S., Sparkman Jr., R., Wilcox, J., 1982. The pretest in survey research: issues and preliminary findings. Journal of Marketing Research 19, 269-273. Levinson, D., Harder, K., Bloomfield, J., Carlson, K., 2006. Waiting tolerance: ramp delay vs. freeway congestion. Transportation Research Part F: Traffic Psychology and Behaviour 9, 1-13.

Levinson, D., Krizek, K., 2008. Planning for Place and Plexus: Metropolitan Land Use and Transport. Routledge, New York City.

Sumalee, A., Kurauchi, F., 2006. Network capacity reliability analysis considering traffic regulation after a major disaster. Networks and Spatial Economics 6 , 205-219.

Wardrop, J., 1952. Some theoretical aspects of road traffic research. In: Proceedings of the Institute of Civil Engineers, Pt. II, vol. 1, pp. 325-378.

Wesemann, L., Hamilton, T., Tabaie, S., Bare, G., 1996. Cost-of-delay studies for freeway closures caused by Northridge earthquake. Transportation Research Record 1559, 67-75.

Wolshon, B., Catarella-Michel, A., Lambert, L., et al, 2006. Louisiana highway evacuation plan for Hurricane Katrina: proactive management of a regional evacuation. Journal of Transportation Engineering 132, 1. 